\title{
Níveis de energia digestível e proteína bruta em rações para alevinos de lambari tambiú 1
}

\author{
Jorge Luiz Vieira Cotan², Eduardo Arruda Teixeira Lanna ${ }^{3}$, Marcos Antonio Delmondes \\ Bomfim ${ }^{4}$, Juarez Lopes Donzele ${ }^{3}$, Felipe Barbosa Ribeiro4, Moacyr Antonio Serafini ${ }^{4}$
}

\footnotetext{
${ }^{1}$ Parte da dissertação apresentada à Universidade Federal de Viçosa.

2 Escola Agrotécnica Federal de Barbacena.

${ }^{3}$ Departamento de Zootecnia - UFV.

${ }^{4}$ Pós-graduação em Zootecnia - UFV.
}

RESUMO - Com o objetivo de determinar os níveis de energia digestível (ED) em função do nível de proteína bruta (PB) da ração para alevinos de lambari tambiú (Astyanax bimaculatus), foram utilizados 600 peixes com 1,30 $\pm 0,01 \mathrm{~g}$, distribuídos em 40 aquários de $100 \mathrm{~L}$, dotados de abastecimento de água, com temperatura controlada e sistema de aeração individual. O experimento foi realizado em um esquema fatorial 5 x 2 (cinco níveis de ED: 2.900, 3.000, 3.100, 3.200 e 3.300 kcal/ $\mathrm{kg}$ combinados com dois níveis de PB: 32,0 e 38,0\%), em delineamento inteiramente ao acaso, com quatro repetições e 15 peixes por unidade experimental. Os peixes foram submetidos à alimentação controlada com base no consumo diário médio dos peixes dos tratamentos com rações contendo nível mais alto de energia $(3.300 \mathrm{kcal} / \mathrm{kg})$ para cada nível protéico, corrigido diariamente, durante 49 dias. Foi avaliado o ganho de peso, a taxa de crescimento específico, os consumos de ração, de PB e de ED, a conversão alimentar, a taxa de eficiência protéica, o rendimento de carcaça, a eficiência de retenção de nitrogênio e os teores de umidade, proteína e gordura corporais. Com o nível de $32 \%$ de $\mathrm{PB}$, foram obtidos maiores consumos de ração e de ED, mais altas taxas de eficiência protéica e de retenção de nitrogênio, menores consumo de PB e rendimento de carcaça, além de reduzida umidade corporal. Com níveis crescentes de ED nas rações com $32 \%$ de $\mathrm{PB}$, os peixes apresentaram menor taxa de crescimento específico, mais baixa taxa de efíciência protéica e maior conversão alimentar, enquanto com as rações com $38 \%$ de PB apresentaram maior rendimento de carcaça. A exigência de ED para lambari tambiú é de $2.900 \mathrm{kcal} / \mathrm{kg}$ para rações com 32 e $38 \%$ de PB.

Palavras-chave: Astyanax bimaculatus, nutrição, ração

\section{Dietary levels of digestible energy and crude protein for lambari tambiú fingerlings}

\begin{abstract}
Six hundred lambari tambiú (Astyanax bimaculatus) averaging initial weight of $1.30 \pm 0.01 \mathrm{~g}$, placed in 40 aquariums $(100 \mathrm{~L})$ with water renewal, controlled temperature and individual aeration, were used to determine the digestible energy (DE) requirements, according to the dietary crude protein (CP) levels. The experiment was analyzed as a $5 \mathrm{x} 2$ factorial scheme (five levels of DE: 2,900, 3,000,3,100,3,200, and 3,300 kcal/kg, combined with two levels of CP: 32 and 38\%), in a completely randomized design with four replicates and fifteen fishes per experimental unit. The fish were submitted to the feeding controlled based on the average daily intake of the treatments with the highest energy level $(3,300 \mathrm{kcal} / \mathrm{kg})$ for each daily corrected protein level, during 49 days. Weight gain, specific growth rate, feed intake, crude protein intake, digestible energy intake, apparent feed:gain ratio, protein efficiency rate, carcass yield, nitrogen retention efficiency, and contents of body humidity, fat and protein were evaluated. Fishes fed diets with $32 \%$ of $\mathrm{CP}$ showed smaller specific growth rate and protein efficiency rate and higher feed:gain ratio. Fishes fed diets with $38 \%$ of $\mathrm{CP}$ showed greater carcass yield. The requirement of digestible energy for lambari tambiú is of $2,900 \mathrm{kcal} / \mathrm{kg}$ for diets with 32 and $38 \%$ of $\mathrm{CP}$.
\end{abstract}

Key Words: Astyanax bimaculatus, diets, nutrition

\section{Introdução}

O lambari tambiú (Astyanax bimaculatus), um peixe da família Characidae e da subfamília Tetragonopteridae, têm sido caracterizado na piscicultura como de crescimento precoce, de hábito alimentar onívoro, alta prolificidade e ciclo de produção curto. Esta espécie atinge maturidade sexual aos quatro meses de idade, possui carne de grande aceitação no mercado consumidor e pode ser encontrada desde rios do Nordeste brasileiro até os da Bacia do Prata (Souza \& Andrade, 1983; Silva et al., 1983; Serafini, 2003).

No Brasil, são necessárias pesquisas sobre nutrição de peixes nativos, visto que suas exigências podem variar 
principalmente de acordo com o hábito alimentar, entre espécies, e a fase de criação, dentro de cada espécie.

Poucas pesquisas tem sido realizadas para determinação das exigências nutricionais dos lambaris visando à formulação de rações completas de menor custo e impacto ambiental, principalmente as utilizadas em sistemas de criação mais intensificados, nos quais o alimento natural é escasso.

Informações sobre o nível adequado de utilização de ED em rações são escassas, mas têm-se observado o uso de $3.200 \mathrm{kcal} / \mathrm{kg}$, que é superior aos níveis determinados para peixes de hábito alimentar similar, o que pode ter sido influenciado pelo nível de PB (38\%) determinado para esta espécie (NRC, 1993; Hayashi et al., 1999; Pezzato et al., 2000; Bomfim et al., 2005; Navarro, 2003; Serafini, 2003).

O desempenho, a composição corporal e a exigência de PB para o lambari tambiú podem ser afetados pelo nível de energia na ração. Os peixes podem modificar seu consumo de alimento de acordo com o nível de energia na ração: ingerindo rações com maior teor de energia podem consumir quantidades menores de proteína, prejudicando seu desenvolvimento.

Este trabalho foi conduzido com o objetivo de determinar a exigência de ED de alevinos de lambari tambiú, em função do teor de PB da ração, visando otimizar o desempenho e a qualidade de carcaça desses peixes.

\section{Material e Métodos}

O experimento foi conduzido nos meses de outubro a dezembro de 2003, durante período de 49 dias, no Laboratório de Nutrição de Peixes do DZO na Universidade Federal de Viçosa (UFV).

Foram utilizados 600 alevinos de 1,30 $\pm 0,01 \mathrm{~g}$, obtidos de mesma desova, em um experimento em esquema fatorial $5 \times 2$ (níveis energéticos $\mathrm{x}$ níveis protéicos), com quatro repetições por tratamento e 15 peixes por unidade experimental.

As composições das rações experimentais encontram-se apresentadas na Tabela 1. As rações foram peletizadas (1 a $2 \mathrm{~mm}$ de diâmetro) e fornecidas em três refeições diárias $(8,12$ e $16 \mathrm{~h})$. Como os peixes podem alimentar-se para satisfazer suas exigências de energia (NRC, 1993), a quantidade de ração fornecida diariamente foi ajustada com base no consumo médio total dos peixes dos tratamentos com nível mais alto de energia $(3.300 \mathrm{kcal} / \mathrm{kg})$ no dia anterior, para cada nível protéico, sendo corrigidos diariamente. As dietas foram fornecidas em pequenas quantidades, possibilitando a ingestão máxima sem ocorrência de perdas, garantindo que, para cada nível protéico, os peixes consumissem quantidades iguais de proteína, fósforo, cálcio e demais nutrientes, evitando confundimento dos resultados em decorrência da variação no consumo de nutrientes. Portanto, os efeitos dos tratamentos sobre as variáveis foram apenas em função da variação do consumo de energia.

Após a leitura matinal da temperatura da água, foi realizada a limpeza diária dos aquários por sifonagem, para retirada das fezes.

Os peixes foram distribuídos em 40 aquários de fibrocimento, revestidos com tinta EPOQUIX, com capacidade para $100 \mathrm{~L}$ de água, com renovação constante de água e vazão de $0,7 \mathrm{~L} / \mathrm{min}$, dotados de sistemas individuais de abastecimento, aeração e escoamento (de fundo).

A água de abastecimento dos aquários, proveniente do sistema de tratamento de água da UFV, foi previamente declorada, utilizando-se tiossulfato de sódio, e aquecida por meio de resistências elétricas. A temperatura foi controlada com um termostato e aferida às 8 e $17 \mathrm{~h}$ com termômetro de bulbo de mercúrio.

O fotoperíodo utilizado foi de 12 horas de luz controlado por timer eletrônico.

Foram avaliados o ganho de peso (GP), o consumo aparente de ração (CAR), a conversão alimentar aparente (CAA), os consumos de proteína bruta (CPB) e de energia digestível (CED), as taxas de crescimento específico (TCE) e de eficiência protéica (TEP) para o ganho de peso, a composição química corporal (teores de umidade, proteína e gordura), o rendimento de carcaça (RC), as taxas de deposição diária de proteína (TDP) e de gordura (TDG) e a eficiência de retenção de nitrogênio (ERN).

Os peixes foram pesados em grupo por unidade experimental, após jejum de 24 horas, no início e ao final do experimento, para determinação do GP.

Para determinação da TCE, foi empregada a equação proposta por Brett \& Groves (1979), utilizando-se transformações logarítmicas.

$$
\mathrm{TCE}=\frac{\log \text { peso final }(\mathrm{g})-\log \text { peso inicial }}{\text { Tempo de experimento (dias) }} \times 100
$$

A CAA foi calculada dividindo-se o consumo aparente de ração pelo ganho de peso dos peixes, a TEP, pela divisão entre o GP dos peixes e o CPB e o RC, pela diferença do peso final dos peixes e das vísceras dividido pelo peso final e multiplicado por 100 .

Para as análises da composição corporal, os lambaris foram insensibilizados, sacrificados e congelados no início ( $5 \%$ dos peixes utilizados no experimento - 30 peixes) e ao final do experimento (seis peixes por unidade experimental [três fêmeas e três machos], com pesos correspondentes ao peso médio da respectiva unidade) e armazenados em freezer. 
Tabela 1 - Composições percentuais, químicas e valores nutricionais das rações experimentais (matéria natural)

Table 1 - Ingredient, chemical and nutritional compositions of the experimental diets (as-fed)

\begin{tabular}{|c|c|c|c|c|c|c|c|c|c|c|}
\hline \multirow{3}{*}{$\begin{array}{l}\text { Nível de proteína bruta } \\
\text { Level of crude protein } \\
\text { Nível de energia digestível } \\
\text { Level of digestible energy }\end{array}$} & \multicolumn{5}{|c|}{$32 \%$} & \multicolumn{5}{|c|}{$38 \%$} \\
\hline & \multirow[t]{2}{*}{2.900} & \multirow[t]{2}{*}{3.000} & \multirow[t]{2}{*}{3.100} & \multirow[t]{2}{*}{3.200} & \multirow[t]{2}{*}{3.300} & \multirow[t]{2}{*}{2.900} & \multirow[t]{2}{*}{3.000} & \multirow[t]{2}{*}{3.100} & \multirow[t]{2}{*}{3.200} & \multirow[t]{2}{*}{3.300} \\
\hline & & & & & & & & & & \\
\hline Farelo de soja (46\%) (Soybean meal) & 54,30 & 54,30 & 54,30 & 54,30 & 54,30 & 69,20 & 69,20 & 69,20 & 69,20 & 69,20 \\
\hline Farinha de peixe (Fish meal) & 9,00 & 9,00 & 9,00 & 9,00 & 9,00 & 10,50 & 10,50 & 10,50 & 10,50 & 10,50 \\
\hline Milho (Corn meal) & 27,39 & 27,39 & 27,39 & 27,39 & 27,39 & 8,40 & 8,40 & 8,40 & 8,40 & 8,40 \\
\hline Amido de milho (Corn starch) & - & - & - & - & - & 4,90 & 4,90 & 4,90 & 4,90 & 4,90 \\
\hline Bagaço de cana (Sugar cane peeling) & 1,20 & 1,20 & 1,20 & 1,20 & 1,20 & - & - & - & - & - \\
\hline Óleo de soja (Soybean oil) & 0,70 & 1,83 & 2,95 & 4,08 & 5,20 & 0,00 & 1,13 & 2,25 & 3,38 & 4,50 \\
\hline Inerte (areia) (Inert - sand) & 4,50 & 3,38 & 2,25 & 1,13 & 0,00 & 4,50 & 3,38 & 2,25 & 1,13 & 0,00 \\
\hline Fosfato bicálcico (Dicalcium phosphate) & 1,55 & 1,55 & 1,55 & 1,55 & 1,55 & 1,30 & 1,30 & 1,30 & 1,30 & 1,30 \\
\hline Calcário calcítico (Limestone) & 0,19 & 0,19 & 0,19 & 0,19 & 0,19 & 0,00 & 0,00 & 0,00 & 0,00 & 0,00 \\
\hline DL-metionina (98\%) (DL-methionine) & 0,00 & 0,00 & 0,00 & 0,00 & 0,00 & 0,03 & 0,03 & 0,03 & 0,03 & 0,03 \\
\hline Vitamina $\mathrm{C}^{1}$ (Vitamin $C$ ) & 0,05 & 0,05 & 0,05 & 0,05 & 0,05 & 0,05 & 0,05 & 0,05 & 0,05 & 0,05 \\
\hline Premix vit. e min. ${ }^{2}$ (Vitamin and mineral mix) & 0,60 & 0,60 & 0,60 & 0,60 & 0,60 & 0,60 & 0,60 & 0,60 & 0,60 & 0,60 \\
\hline Sal (Salt) & 0,50 & 0,50 & 0,50 & 0,50 & 0,50 & 0,50 & 0,50 & 0,50 & 0,50 & 0,50 \\
\hline $\mathrm{BHT}^{3}$ & 0,02 & 0,02 & 0,02 & 0,02 & 0,02 & 0,02 & 0,02 & 0,02 & 0,02 & 0,02 \\
\hline
\end{tabular}

Composição calculada

Calculated composition

\begin{tabular}{|c|c|c|c|c|c|c|c|c|c|c|}
\hline Proteína bruta, $\%{ }^{4}$ (Crude protein, \%) & 32,00 & 32,00 & 32,00 & 32,00 & 32,00 & 38,00 & 38,00 & 38,00 & 38,00 & 38,00 \\
\hline Energia digestível, $\mathrm{kcal} / \mathrm{kg}^{5}$ (Digestible energy, $\mathrm{kcal} / \mathrm{kg}$ ) & 2.901 & 3.001 & 3.101 & 3.202 & 3.302 & 2.900 & 3.001 & 3.101 & 3.202 & 3.302 \\
\hline Extrato etéreo, $\%{ }^{4}$ (Ether extract, \%) & 3,07 & 4,19 & 5,30 & 6,42 & 7,53 & 2,04 & 3,16 & 4,27 & 5,39 & 6,5 \\
\hline Fibra bruta, $\% 4$ (Crude fiber, \%) & 4,34 & 4,34 & 4,34 & 4,34 & 4,34 & 4,33 & 4,33 & 4,33 & 4,33 & 4,33 \\
\hline Cálcio total, $\%^{5}$ (Total calcium, \%) & 1,18 & 1,18 & 1,18 & 1,18 & 1,18 & 1,18 & 1,18 & 1,18 & 1,18 & 1,18 \\
\hline Fósforo digestível, $\%^{5}$ (Digestible phosphorus, \%) & 0,50 & 0,50 & 0,50 & 0,50 & 0,50 & 0,50 & 0,50 & 0,50 & 0,50 & 0,50 \\
\hline Metionina + Cistina, $\%^{5}$ (Methyonine + Cistine, \%) & 1,00 & 1,00 & 1,00 & 1,00 & 1,00 & 1,18 & 1,18 & 1,18 & 1,18 & 1,18 \\
\hline Lisina, $\%{ }^{5}$ (Lysine, \%) & 1,92 & 1,92 & 1,92 & 1,92 & 1,92 & 2,34 & 2,34 & 2,34 & 2,34 & 2,34 \\
\hline Relação ED/PB (kcal/g) (DE:CP ratio) & 9,06 & 9,38 & 9,69 & 10,01 & 10,32 & 7,63 & 7,90 & 8,16 & 8,43 & 8,69 \\
\hline
\end{tabular}

1 Vit. C: ácido ascórbico (ascorbic acid).

2 Premix vitamínico comercial (vitamin mix) (5 kg/t), com níveis de garantia por quilograma do produto: Vit. A, 1.200.000 UI; Vit. D 3 , 200.000 UI; Vit. E, 12.000 mg; Vit. $\mathrm{K}_{3}, 2.400 \mathrm{mg}$; Vit. $\mathrm{B}_{1}, 4.800 \mathrm{mg}$; Vit. $\mathrm{B}_{2}, 4.800 \mathrm{mg}$; Vit. $\mathrm{B}_{6}, 4.000 \mathrm{mg}$; Vit. $\mathrm{B}_{12}, 4.800 \mathrm{mg}$; ác. fólico (folic acid), 1.200 mg; pantotenato de Ca (panthotenic acid), $12.000 \mathrm{mg}$; Vit. C, $48.000 \mathrm{mg}$; biotina (biotin), $48 \mathrm{mg}$; cloreto de colina (choline), $108.000 \mathrm{mg}$; niacina (niacin), $24.000 \mathrm{mg}$; e premix mineral comercial (mineral mix) (1 kg/t), com níveis de garantia por quilograma do produto: Fe, $50.000 \mathrm{mg} ; \mathrm{Cu}, 3.000 \mathrm{mg} ; \mathrm{Mn}, 20.000 \mathrm{mg} ; \mathrm{Zn}, 3.000 \mathrm{mg} ; \mathrm{I}, 100 \mathrm{mg} ; \mathrm{Co}, 10 \mathrm{mg}$ Se, $100 \mathrm{mg}$

3 Butil Hidroxitolueno.

4 Com base nas análises de laboratório LNA/UFV (Based on lab analyses - LNA/DZO).

5 Com base nos valores propostos pelo NRC (1993) e por Rostagno et al. (2000) [Based on values proposed by NRC (1993) and Rostagno et al. (2000)]

As análises dos ingredientes das rações e das amostras dos peixes foram realizadas no Laboratório de Nutrição Animal do Departamento de Zootecnia (LNA/DZO) da UFV, conforme procedimentos descritos por Silva \& Queiroz(2002).

A ERN, expressa em porcentagem, foi calculada pela diferença do nitrogênio corporal final e o inicial, dividido pelo nitrogênio total consumido, multiplicado por 100 .

A TDP e a TDG foram determinadas, respectivamente, pela diferença da proteína e da gordura corporal final e inicial, em mg, dividido pelo número de dias.

As análises estatísticas foram realizadas utilizando-se o programa SAEG - Sistema de Análises Estatísticas e Genéticas (UFV, 1993).

Os dados foram interpretados por análises de variância e regressão. Independentemente da significância ou da interação entre os níveis de proteína e energia digestível, optou-se pelo desdobramento da interação, evidenciando os efeitos dos níveis de energia para cada nível protéico, em razão dos interesses em estudo. Os efeitos dos níveis de energia digestível foram analisados mediante o uso dos modelos de regressão linear, quadrático ou descontínuo "Linear Response Plateau" (LRP), conforme o melhor ajustamento obtido para cada variável, com base na significância dos coeficientes de regressão pelo teste $\mathrm{F}$, no coeficiente de determinação $\left(\mathrm{R}^{2}=\right.$ S.Q.Reg./S.Q.Tratamento), na soma de quadrado dos desvios e no fenômeno em estudo.

\section{Resultados e Discussão}

O sistema de abastecimento de água e de aeração possibilitou o controle da temperatura e da aeração entre os tratamentos durante o período experimental. A temperatura da água foi mantida em $28,9 \pm 2,2^{\circ} \mathrm{C}$, o $\mathrm{pH}$ em $6,8 \pm 0,15$ e o oxigênio dissolvido em $6,9 \pm 0,3 \mathrm{ppm}$ - valores estabelecidos como ideais para a criação de lambari tambiú (Garutti, 2003). 
Tabela 2 - Ganho de peso (GP), taxa de crescimento específico (TCE), consumo aparente de ração (CAR), conversão alimentar aparente (CAA), consumos de proteína (CPB) e energia digestível (CED) de lambaris tambiú, de acordo com os níveis de ED e PB da ração

Table 2 - Weight gain (WG), specifc growth rate (SGR), apparent feed intake (AFI), apparent feed/gain ratio (FCR) crude protein intake $(C P I)$ and digestible energy intake (DEI) of lambaris tambiu according to the dietary digestible energy $(D E)$ and crude protein $(C P)$ levels

\begin{tabular}{|c|c|c|c|c|c|c|}
\hline \multirow[t]{2}{*}{$\begin{array}{l}\mathrm{PB}(\%) \\
C P\end{array}$} & \multicolumn{5}{|c|}{$\begin{array}{c}\mathrm{ED}(\mathrm{kcal} / \mathrm{kg}) \\
D E\end{array}$} & \multirow[t]{2}{*}{$\mathrm{CV}$} \\
\hline & 2.900 & 3.000 & 3.100 & 3.200 & 3.300 & \\
\hline \multicolumn{7}{|c|}{ GP $(W G) \quad(\mathrm{g})$} \\
\hline $32 \%$ & 3,31 & 3,07 & 3,25 & 3,23 & 2,71 & 10,57 \\
\hline $38 \%$ & 2,89 & 3,22 & 2,96 & 2,96 & 3,01 & \\
\hline Média & 3,10 & 3,14 & 3,10 & 3,09 & 2,86 & \\
\hline \multicolumn{7}{|c|}{ TCE (SGR) (\%) } \\
\hline $32 \%^{1}$ & 1,12 & 1,07 & 1,11 & 1,10 & 0,99 & 6,20 \\
\hline $38 \%$ & 1,04 & 1,10 & 1,05 & 1,05 & 1,06 & \\
\hline \multicolumn{7}{|c|}{ CRA $(A F I)(\mathrm{g})$} \\
\hline $32 \%$ & 5,53 & 5,53 & 5,53 & 5,53 & 5,53 & 0,17 \\
\hline $38 \%$ & 5,27 & 5,27 & 5,27 & 5,27 & 5,27 & \\
\hline Média & 5,40 & 5,40 & 5,40 & 5,40 & 5,40 & \\
\hline \multicolumn{7}{|c|}{ CAA $(F C R)(\mathrm{g} / \mathrm{g})$} \\
\hline $32 \%{ }^{1}$ & 1,67 & 1,82 & 1,72 & 1,73 & 2,06 & 10,88 \\
\hline $38 \%$ & 1,84 & 1,65 & 1,80 & 1,80 & 1,78 & \\
\hline \multicolumn{7}{|c|}{ CPB (CPI) (g) } \\
\hline $32 \%$ & 1,77 & 1,77 & 1,77 & 1,77 & 1,77 & 0,18 \\
\hline $38 \%$ & 2,00 & 2,00 & 2,00 & 2,00 & 2,00 & \\
\hline Média & 1,88 & 1,88 & 1,88 & 1,88 & 1,88 & \\
\hline \multicolumn{7}{|c|}{ CED (DEI) (kcal/g) } \\
\hline $32 \%^{2}$ & 16,04 & 16,58 & 17,15 & 17,69 & 18,64 & 5,11 \\
\hline $38 \%^{2}$ & 15,28 & 15,80 & 16,34 & 16,85 & 17,39 & \\
\hline
\end{tabular}

CV - Coeficiente de variação (coefficient of variation).

1 Efeito linear $(P<0,05)$ [Linear effect $(P<0.05)$ ].

2 Efeito linear $(P<0,01)$ [Linear effect $(P<0.01)]$.

Os resultados médios do GP, da TCE, do CRA, da CAA, do CPB e do CED podem ser visualizados na Tabela 2 e a TEP para ganho de peso, o RC, a ERN, a TDP e a TDG, na Tabela 3.

Embora o teor energético ( $3.300 \mathrm{kcal} / \mathrm{kg}$ de ED) das rações tenha sido estabelecido para determinação dos consumos dos peixes dos demais tratamentos, em cada nível protéico, os peixes alimentados com rações contendo $32 \%$ de PB consumiram mais ração e, conseqüentemente, mais ED que aqueles alimentados com rações com $38 \%$ de PB. Esse efeito não pode ser sustentado pelo fato de que peixes se alimentam para satisfazer, primariamente, suas exigências em energia (Page \& Andrews, 1973; Lee \& Putnam, 1973; El-Dahhar \& Lovell, 1995; Sampaio et al., 2000). No entanto, corroboram as observações de Bomfim et al. (2005) e a teoria de Winfree \& Stickney (1981) de que os peixes podem satisfazer suas exigências em proteína conforme a variação no consumo.
Tabela 3 - Rendimento de carcaça (RC), eficiência de retenção de nitrogênio (ERN), taxas de deposição de proteína (TDP) e de gordura (TDG) e taxa de eficiência protéica (TEP) de lambaris tambiú, de acordo com os níveis de energia digestível (ED) e proteína bruta da ração (PB)

Table 3 - Carcass yield (CY), nitrogen retention efficiency (NRE), protein deposition rate (PDR), fat deposition rate (FDR), and protein efficiency rate (PER) of lambaris tambiu according to the dietary digestible energy $(D E)$ and crude protein $(C P)$ levels

\begin{tabular}{|c|c|c|c|c|c|c|}
\hline \multirow[t]{2}{*}{$\begin{array}{l}\mathrm{PB}(\%) \\
C P\end{array}$} & \multicolumn{5}{|c|}{$\begin{array}{c}\mathrm{ED}(\mathrm{kcal} / \mathrm{kg}) \\
D E \\
\end{array}$} & \multirow[t]{2}{*}{$\mathrm{CV}$} \\
\hline & 2.900 & 3.000 & 3.100 & 3.200 & 3.300 & \\
\hline \multicolumn{7}{|c|}{$\mathrm{RC}(C Y)(\%)$} \\
\hline $32 \%$ & 87,28 & 86,99 & 87,57 & 85,48 & 87,22 & 1,14 \\
\hline $38 \% 1$ & 86,38 & 87,95 & 87,88 & 87,60 & 88,33 & \\
\hline \multicolumn{7}{|c|}{ ERN (NRE) (\%) } \\
\hline $32 \%$ & 29,24 & 27,87 & 29,63 & 28,69 & 24,58 & 11,54 \\
\hline $38 \%$ & 23,90 & 25,95 & 24,37 & 23,60 & 23,86 & \\
\hline Média & 26,57 & 26,91 & 27,00 & 26,14 & 24,22 & \\
\hline \multicolumn{7}{|c|}{$\mathrm{TDP}(P D R)(\mathrm{mg} / \mathrm{dia})$} \\
\hline $32 \%$ & 10,56 & 10,06 & 10,70 & 10,36 & 8,88 & 3,91 \\
\hline $38 \%$ & 9,77 & 10,60 & 9,96 & 9,64 & 9,75 & \\
\hline Média & 10,16 & 10,33 & 10,33 & 10,00 & 9,31 & \\
\hline \multicolumn{7}{|c|}{ TDG (FDR) (mg/dia) } \\
\hline $32 \%$ & 7,35 & 7,70 & 7,61 & 8,12 & 6,86 & 10,87 \\
\hline $38 \%$ & 5,87 & 8,01 & 6,64 & 8,23 & 7,11 & \\
\hline Média & 6,61 & 7,85 & 7,12 & 8,17 & 6,98 & \\
\hline \multicolumn{7}{|c|}{ TEP $(P E R)(\mathrm{g} / \mathrm{g})$} \\
\hline $32 \%^{2}$ & 1,88 & 1,74 & 1,83 & 1,83 & 1,53 & 10,50 \\
\hline $38 \%$ & 1,44 & 1,61 & 1,48 & 1,48 & 1,50 & \\
\hline
\end{tabular}

CV - Coeficiente de variação (coefficient of variation).

1 Efeito linear $(P<0,05)[$ Linear effect $(P<0.05)]$.

2 Efeito linear $(P<0,01)$ [Linear effect $(P<0.01)$ ].

Ainda assim, o CPB dos peixes que receberam ração com $32 \%$ de $\mathrm{PB}$ foi inferior $(\mathrm{P}<0,05)$ ao daqueles alimentados com $38 \%$ de PB. O GP, a CAA e a TCE não variaram $(\mathrm{P}>0,05)$ entre os níveis de PB. É possível que o CPB observado nos peixes alimentados com $32 \%$ de PB tenha sido suficiente para atender às exigências em proteína e que as rações contendo 38\% de PB tenham fornecido proteína em excesso. Esta hipótese pode ser reforçada pelos menores valores de TEP e ERN obtidos com este nível protéico (Tabela 3). Nesse caso, o excesso de proteína pode ter sido utilizado, quando absorvido, como fonte de energia.

De acordo com Sampaio et al. (2000), o consumo excessivo de proteínas pode reduzir a eficiência de utilização da proteína (TEP e ERN) pelos peixes, de modo que, parte desta proteína, quando não utilizada para síntese protéica, pode ser desviada para deposição na forma de energia, lipogênese ou gliconeogênese.

Quando se utilizou a ração com $32 \%$ de PB, o nível de ED influenciou a TCE e a TEP, que diminuíram $(\mathrm{P}<0,05)$ de forma linear, o $\mathrm{CED}(\mathrm{P}<0,01)$ e a $\mathrm{CAA}(\mathrm{P}<0,05)$, que aumentaram linearmente conforme equações constantes na Tabela 4. 
Na ração com $32 \%$ de $\mathrm{PB}$ e 3.300 kcal de ED, os resultados obtidos, na maioria das variáveis, diferiram da média dos outros níveis de energia, o que pode ter ocorrido em razão do alto nível de EE na ração $(7,5 \%)$, que provavelmente ultrapassou a capacidade de digestão de lipídeos dos peixes, semelhante ao observado por Vidal Jr. (2000), em pesquisa conduzida com tambaquis, podendo também influenciar negativamente a digestão de outros nutrientes.

A possível menor digestibilidade da energia pode ter influenciado negativamente o GP, a TCE e a CAA, superestimando a CED, que não foi determinada, e sim calculada, provocando o efeito linear observado.

Meurer et al. (2002) sugeriram que a utilização de níveis excessivos de lipídeos, com a elevação da densidade energética, pode reduzir a disponibilidade de aminoácidos para síntese de proteína corporal, resultando em menor TCE, CAA e, principalmente, TEP.

O nível de energia da ração dos peixes alimentados com rações contendo $38 \%$ de $\mathrm{PB}$ influenciou o $\mathrm{CED}(\mathrm{P}<0,01)$ e o
$\mathrm{RC}(\mathrm{P}<0,05)$, que aumentaram linearmente com a elevação do nível de ED da ração.

Apesar da variação linear no RC, o modelo "Linear Response Plateau" - LRP foi o que melhor se ajustou aos dados, estimando em $2.999 \mathrm{kcal}$ de ED/kg o nível no qual ocorreu um platô (Figura 1).

Os piores resultados numéricos dos parâmetros avaliados obtidos com as rações contendo $38 \%$ de $\mathrm{PB}$ com 2.900 e mais que $3.000 \mathrm{kcal}$ de $\mathrm{ED} / \mathrm{kg}$ podem ser indicativos de que, no primeiro caso, a quantidade de energia ingerida tenha sido insuficiente para atender às exigências para os gastos com mantença e metabolização da proteína ingerida (anabolismo e o catabolismo excedente) - hipótese reforçada pelos menores valores de TDG e, no segundo caso, provavelmente os baixos níveis de carboidratos, associados ao excesso de proteína consumido, tenham proporcionado menor relação proteína:carboidrato (Bomfim et al., 2005), promovendo a ativação das enzimas gliconeogênicas e reduzindo a utilização da fração protéica para o crescimento.

Tabela 4 - Valores de exigência, coeficientes de determinação e equações de regressão ajustadas para ganho de peso (GP), taxa de crescimento específico (TCE), consumo aparente de ração (CAR), conversão alimentar aparente (CAA), consumos de proteína bruta (CPB) e de energia digestível (CED), rendimento de carcaça (RC), eficiência de retenção de nitrogênio (ERN), taxas de deposição de proteína (TDP) e gordura (TDG) e taxa de eficiência protéica (TEP) de lambaris tambiú, de acordo com os níveis de energia digestível de proteína bruta (PB) da ração

Table 4 - Requirement values, coefficients of determination and regression equation adjusted for the variables, weight gain (WG), specific growth rate (SGR), apparent feed intake (AFI), apparent feed/gain ratio (FCR), crude protein intake (CPI), digestible energy intake (DEI), carcass yield (CY) nitrogen retention efficiency (NRE), protein deposition rate (PDR), fat deposition rate (FDR), protein efficiency rate (PER) of lambaris tambiu according to the dietary digestible energy $(D E)$ and crude protein $(C P)$ levels

Modelos quadrático, linear e LRP

$L R P$, linear and quadractic models

\begin{tabular}{|c|c|c|c|c|}
\hline $\begin{array}{l}\text { Variável } \\
\text { Variable }\end{array}$ & $\begin{array}{l}\text { PB (\%) } \\
C P(\%)\end{array}$ & $\begin{array}{l}\text { Equações ajustadas } \\
\text { Adjusted equation }\end{array}$ & $\begin{array}{l}\text { Exigência }(\mathrm{kcal} / \mathrm{kg}) \\
\text { Requirement }\end{array}$ & $\mathrm{R}^{2}$ \\
\hline \multirow[t]{2}{*}{$\mathrm{GP}(W G)(\mathrm{g})$} & 32 & $\hat{\mathrm{Y}}=3,11$ & 2.900 & - \\
\hline & 38 & $\hat{\mathrm{Y}}=3,01$ & 2.900 & - \\
\hline \multirow[t]{2}{*}{$\operatorname{TCE}(S R G)(\% / \mathrm{dia})$} & 32 & $\hat{Y}=1,755-0,0002175^{*} X$ & 2.900 & 0,47 \\
\hline & 38 & $\hat{\mathrm{Y}}=1,06$ & 2.900 & - \\
\hline \multirow[t]{2}{*}{ CRA $(A F I)(\mathrm{g})$} & 32 & $\hat{\mathrm{Y}}=5,53$ & - & - \\
\hline & 38 & $\hat{\mathrm{Y}}=5,27$ & - & - \\
\hline \multirow[t]{2}{*}{ CAA $(F C R)(\mathrm{g} / \mathrm{g})$} & 32 & $\hat{Y}=-0,3075+0,0006793^{*} \mathrm{X}$ & 2.900 & 0,49 \\
\hline & 38 & $\hat{Y}=1,77$ & 2.900 & - \\
\hline \multirow[t]{2}{*}{$\mathrm{CPB}(C P I)(\mathrm{g})$} & 32 & $\hat{\mathrm{Y}}=1,77$ & - & - \\
\hline & 38 & $\hat{\mathrm{Y}}=2,00$ & - & - \\
\hline \multirow[t]{2}{*}{$\mathrm{CED}(D E I) \quad(\mathrm{kcal} / \mathrm{kg})$} & 32 & $\hat{Y}=0,059+0,00551^{* *} X$ & 3.300 & 0,99 \\
\hline & 38 & $\hat{\mathrm{Y}}=0,005+0,00527^{* *} \mathrm{X}$ & 3.300 & 0,99 \\
\hline \multirow[t]{2}{*}{$\mathrm{RC}(R Y)(\%)$} & 32 & $\hat{Y}=86,91$ & 2.900 & - \\
\hline & 38 & LRP $\hat{Y}=41,0081+0,00156^{*} X($ platô $=87,94)$ & 2.999 & 1.00 \\
\hline \multirow[t]{2}{*}{ ERN (NRE) (\%) } & 32 & $\hat{Y}=28,00$ & 2.900 & - \\
\hline & 38 & $\hat{\mathrm{Y}}=24,34$ & 2.900 & - \\
\hline \multirow[t]{2}{*}{ TDP (mg/dia) (PDR, mg/day) } & 32 & $\hat{\mathrm{Y}}=10,02$ & 2.900 & - \\
\hline & 38 & $\hat{\mathrm{Y}}=9,94$ & 2.900 & - \\
\hline \multirow[t]{2}{*}{$\mathrm{TDG}(\mathrm{mg} / \mathrm{dia})(F D R, m g / d a y)$} & 32 & $\hat{\mathrm{Y}}=7,53$ & 2.900 & - \\
\hline & 38 & $\hat{\mathrm{Y}}=7,17$ & 2.900 & - \\
\hline \multirow[t]{2}{*}{ TEP (PER) $(\mathrm{g} / \mathrm{g})$} & 32 & $\hat{\mathrm{Y}}=3,5728-0,0005849^{* *} \mathrm{X}$ & 2.900 & 0,50 \\
\hline & 38 & $\hat{\mathrm{Y}}=1,50$ & 2.900 & - \\
\hline
\end{tabular}

${ }^{*}(\mathrm{P}<0,05) \mathrm{e}^{* *}(\mathrm{P}<0,01)$ pelo teste $\mathrm{F}\left[{ }^{*}(P<0.05)\right.$ and ${ }^{* *}(P<0.01)$ by F test. $]$

$\mathrm{R}^{2}=$ coeficiente de determinação (coefficient of determination). 


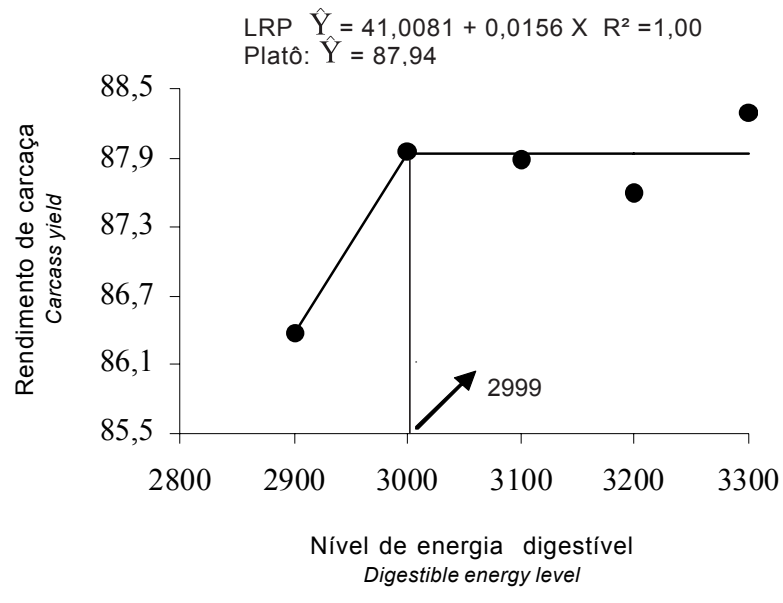

Figura 1 - Efeito dos níveis de energia da ração com $38 \%$ de proteína bruta sobre o rendimento de carcaça de alevinos de lambari tambiú.

Figure 1 - Carcass yield of lambari fingerlings, according to the energy levels of diets with $38 \%$ crude protein.

Os valores médios da composição corporal dos peixes podem ser visualizados na Tabela 5 .

Os peixes alimentados com rações contendo $32 \%$ de $\mathrm{PB}$ apresentaram menores $(\mathrm{P}<0,05)$ teores de umidade corporal que aqueles que receberam $38 \%$ de PB. Este resultado foi semelhante ao observado por Serafini (2003), em alevinos de lambari tambiú, e por Bomfim et al. (2005), em curimbatá.

A composição corporal em energia foi influenciada apenas nos peixes alimentados com as rações com $38 \%$ de PB, observando-se que a elevação do teor energético da ração aumentou $(\mathrm{P}<0,05)$ de forma linear o teor de gordura e proporcionou variação quadrática no teor de umidade $(\mathrm{P}<0,05)$, que reduziu até o valor estimado de $3.119 \mathrm{kcal}$ de $\mathrm{ED} / \mathrm{kg}$ (Tabela 6).

Os teores de proteína corporal não foram influenciados $(\mathrm{P}>0,05)$ pelo aumento dos níveis de energia, o que reforça a possibilidade de excesso de lipídeos, ultrapassando a
Tabela 5 - Composição corporal de lambaris, de acordo com os níveis de energia digestível (ED) e proteína bruta (PB) na ração

Table 5 - Body composition, according to the dietary digestible energy and crude protein levels

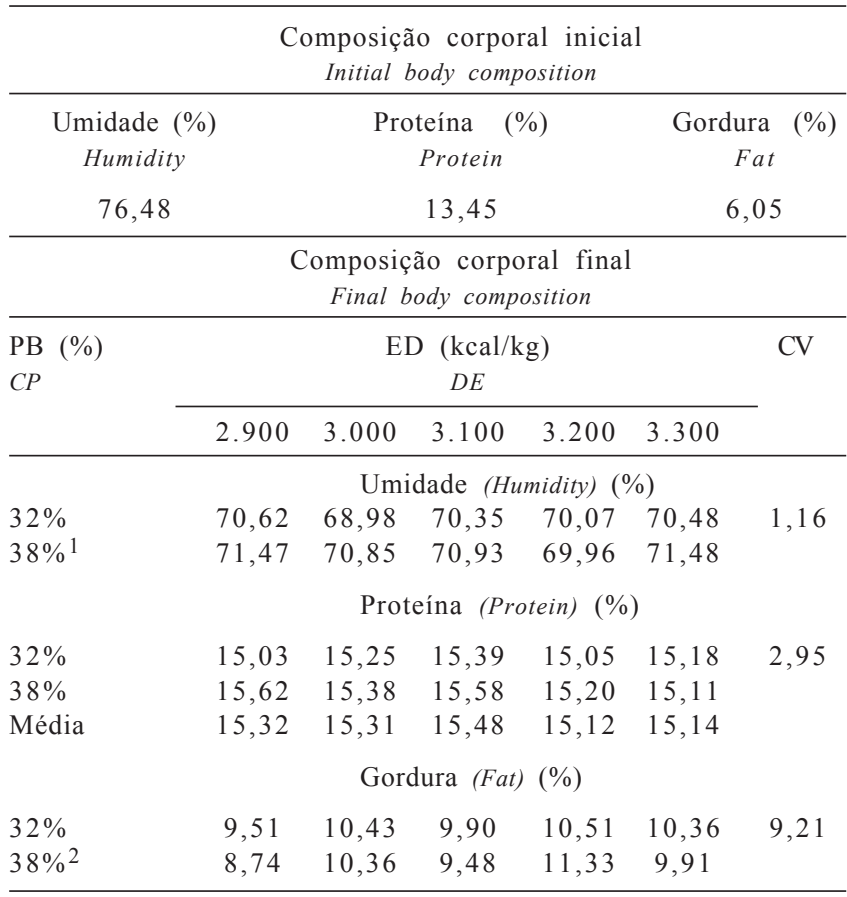

CV - Coeficiente de variação (coefficient of variation).

${ }^{1}$ Efeito quadratico $(P<0,05)$ [Quadractic effect $(P<0.05)$ ].

2 Efeito linear $(P<0,05)$ [Linear effect $(P<0.05)]$.

capacidade de digestão do peixe, podendo ter provocado o não-aproveitamento da proteína para deposição.

Os resultados obtidos corroboram os relatados por outros autores (Garling \& Wilson, 1976; Lee \& Putmam, 1973; Page \& Andrews, 1973; Parazo,1990; Santiago \& Reys, 1991; Hernandez et al., 1995; Fernandes et al., 2000; Sampaio et al., 2000; Sá \& Fracalossi, 2002) que constataram que rações com maior relação energia:proteína resultam em maior concentração de lipídios e mais alta taxa de deposição de gordura, além de menor concentração de proteína corporal.

Tabela 6 - Valores de exigência, coeficientes de determinação e equações de regressão ajustadas para umidade corporal (UM), proteína corporal (PB) e gordura corporal (G) de lambari tambiú, de acordo com os níveis de ED e PB da ração

Table 6 - Requirements values, coefficients of determination and regression equation adjusted for body humidity $(H)$, protein $(C P)$ and fat $(F)$ of lambaris tambiu according to the levels of the dietary digestible energy and crude protein levels

\begin{tabular}{|c|c|c|c|c|}
\hline \multirow{3}{*}{$\begin{array}{l}\text { Variável } \\
\text { Variable }\end{array}$} & \multirow{3}{*}{$\begin{array}{l}\text { PB (\%) } \\
C P(\%)\end{array}$} & \multicolumn{3}{|c|}{$\begin{array}{l}\text { Modelos quadrático e linear } \\
\text { Linear and quadractic models }\end{array}$} \\
\hline & & Equações ajustadas & Exigência $(\mathrm{kcal} / \mathrm{kg})$ & $\mathrm{R}^{2}$ \\
\hline & & Adjusted equation & Requirement & \\
\hline \multirow[t]{2}{*}{$\mathrm{UM}(H)(\%)$} & 32 & $\hat{\mathrm{Y}}=70,10$ & - & - \\
\hline & 38 & $\hat{Y}=72,82-1,4779 X+0,00002321^{*} X^{2}$ & 3.100 & 0,53 \\
\hline $\mathrm{PB}(C P)(\%)$ & 32 & $\hat{Y}=15,18$ & - & - \\
\hline & 38 & $\hat{\mathrm{Y}}=8,984+0,328^{*} \mathrm{X}$ & 3.300 & 0,29 \\
\hline
\end{tabular}

* $(\mathrm{P}<0,05)$ pelo teste $\mathrm{F}\left[^{\star}(P<0.05)\right.$ of $F$ test $]$.

$\mathrm{R}^{2}=$ coeficiente de determinação (coefficient of determination). 
Considerando os resultados deste trabalho, pode-se inferir que, para rações com 32 ou $38 \%$ de $\mathrm{PB}$, o nível de ED adequado é de $2.900 \mathrm{kcal} / \mathrm{kg}$.

\section{Conclusões}

A exigência de energia digestível para alevinos de lambari tambiú é de $2.900 \mathrm{kcal} / \mathrm{kg}$ para rações com 32 ou $38 \%$ de PB.

\section{Literatura Citada}

BOMFIM, M.A.D.; LANNA, E.A.T.; SERAFINI, M.A. et al. Proteína bruta e energia digestível em dietas para alevinos de curimbatá. Revista Brasileira de Zootecnia, v.34, n.6, p.1795-1806, 2005 .

BRETT, J.R.; GROVES, T.D.D. Physiological energetics. In: HOAR, W.S.; RANDALL, D.J.; BRETT, J.R. (Eds.). Fish physiology. New York: Academic Press, 1979. v.3, p.279-352.

El-DAHHAR, A.A.; LOVELL, R.T. Effect of protein to energy ratio in purified diets on growth performance, feed utilization and body composition of mossambique tilapia, Oreochromis mossambicus (Peters). Aquaculture Research, v.26, p.451457, 1995.

FERNANDES, J.B.K.; CARNEIRO, D.J.; SAKOMURA, N.K. Fontes e níveis de proteína bruta em dietas para alevinos de pacu, (Piaractus mesopotamicus). Revista Brasileira de Zootecnia, v.29, n.3, p.646-653, 2000.

FURUYA, V.R.B.; HAYASHI, C.; FURUYA, W.M. et al. Influência de plâncton, dieta artificial e sua combinação, sobre o crescimento, sobrevivência de larvas de curimbatá (Prochilodus lineatus). Acta Scientiarum, v.21, n.3, p.699-703, 1999.

GALDIOLI, E.M.; HAYASHI, C.; SOARES, C.M. et al. Substituição da proteína do farelo de soja pela proteína do farelo de canola em rações para alevinos de curimbatá (Prochilodus lineatus V.). Revista Brasileira de Zootecnia, v.31, n.2, p.552-559, 2002.

GARLING, D.L.; WILSON, R.P. Optimum dietary protein to energy ratio for channel catfish, Ictalurus punctatus. Journal Nutrition, v.106, p.1368-1375, 1976.

GARUTTI, V. Piscicultura ecológica. São Paulo: Editora UNESP, 2003. 332p.

HAYASHI, C; GALDIOLI, E.M; NAGAE, M.Y. et al. Exigência de proteína para alevinos de Lambari (Astyanax bimaculatus) (Pisces: Characidae). In: REUNIÃO ANUAL DA SOCIEDADE BRASILEIRA DE ZOOTECNIA, 36., 1999, Porto Alegre. Anais... São Paulo: Gmosis, 1999. CD-ROM. Pequenos animais. PEQ-024

HERNANDEZ, M.; TAKEUCHI, T.; WATANABE, T. Effect of dietary energy sources on the utilization of protein by Colossoma macropomum fingerlings. Fisheries Science, v.61, n.3, p.507-511, 1995.

LEE, D.J.; PUTNAM, G.B. The response of rainbow trout to varying protein/energy ratios in a test diet. Journal Nutrition, v.103, p.916-922, 1973.

MEURER, F.; HAYASHI, C.; BOSCOLO, W.R. et al. Lipídeos na alimentação de alevinos revertidos de tilápia do Nilo (Oreochromis niloticus, L.) Revista Brasileira de Zootecnia, v.31, n.2, p.566-573, 2002.

NATIONAL RESEARCH COUNCIL - NRC. Nutrient requirements of fish. Washington, D.C.: National Academy of Science, 1993. 105p.
NAVARRO, R.D. Níveis de energia digestível em dietas para piauçu (Leporinus macrocephalus, SPIX 1829) (peixe anastomideo) em estágio pós-larval. Viçosa, MG: Universidade Federal de Viçosa, 2003. 54p. Dissertação (Mestrado em Zootecnia) - Universidade Federal de Viçosa, 2003.

PAGE, J.W.; ANDREWS, J.W. Interactions of dietary levels of protein and energy on channel catfish (Ictalurus punctatus). Journal Nutrition, n.103, p.1339-1346, 1973.

PARAZO, M.M. Effect of dietary protein and energy level on growth, protein utilization and carcass composition of rabbitfish, Siganus guttatus. Aquaculture, v.86, p.41-49, 1990.

PEZZATO, L.E., BARROS, M.M., PEZZATO, A.C. et al. Relación energia/proteína en la nutrición de alevinos de piauçú (Leporinus macrocephalus). Revista de Medicina Veterinária y Zootecnia, v.1, p.2-6, 2000 .

ROSTAGNO, R.S.; ALBINO, L.F.T.; DONZELE, J.L. et al. Tabelas brasileiras para aves e suínos - composição de alimentos e exigências nutricionais. 2.ed. Viçosa, MG: Universidade Federal de Viçosa, 2000. 141p.

SÁ, M.V.C.; FRACALOSSI, D.M. Exigência protéica e relação energia/proteína para alevinos de piracanjuba (Brycon orbigyanus). Revista Brasileira de Zootecnia, v.31, n.1, p.1-10, 2002.

SAMPAIO, A.M.B.; KUBITZA, F.; CYRINO, J.E.P. Relação energia:proteína na nutrição do tucunaré. Scientia Agrícola, v. 57, n.2, p.213-219, 2000

SANTIAGO, C.B.; REYES, O.F. Optimum dietary protein level for growth of bighead carp (Aristichthys nobilis) fry in a static water system. Aquaculture, v.93, p.155-165, 1991.

SERAFINI, M.A. Níveis de proteína em dietas de lambari tambiú dos 0,7 aos 4,8 gramas de peso. Viçosa, MG: Universidade Federal de Viçosa, 2003. 25p. Dissertação (Mestrado em Zootecnia) - Universidade Federal de Viçosa, 2003.

SILVA, D.J.; QUEIROZ, A.C. Análise de alimentos (métodos químicos e biológicos). 3.ed. Viçosa, MG: Universidade Federal de Viçosa, 2002. 235p

SILVA, J.M.F.; ANDRADE, D.R.; TEIXEIRAS, S.M. Alimentação de lambari, Astianax bimaculatus (Linnaeus, 1758) com excremento de suínos e ração. In: REUNIÃO ANUAL PARA O PROGRESSO DA CIÊNCIA, 35., 1983, Belém. Anais... Belém: 1983. p.736-737.

SOUZA, J.R.; ANDRADE, O.R. Dados preliminares sobre nutrição de Astyanax bimaculatus (LINNAEUS, 1958), Pisces: Characidae. Seiva, v.2, n.90, p.81-83, 1983.

UNIVERSIDADE FEDERAL DE VICCOSA - UFV. Central de processamento de dados UFV/CPD. Manual de utilização do programa SAEG (Sistema para análises estatísticas e genéticas). Viçosa, MG: Universidade Federal de Viçosa, 1993. 59p.

VIDAL JR., M.V. Técnicas de determinação de digestibilidade e determinação da digestibilidade de nutrientes de alimentos para tambaqui (Colossoma macropomum). Viçosa, MG: Universidade Federal de Viçosa, 2000. 96p. Tese (Doutorado em Zootecnia) - Universidade Federal de Viçosa, 2000.

WINFREE, R.A.; STICKNEY, R.R. Started diets for channel catfish effects of dietary protein on growth and carcass composition. The Progressive Fish-Culturist, v.46, n.2, p.79-86, 1981. 